\title{
Capsule Commentary on Liu et al., Trends in Self-reported Prediabetes and Metformin Use in the United States: NHANES 2005-2014
}

\author{
Elizabeth A. Richey, MD, MS and David S. Smith, MD
}

Yale Health and Yale School of Medicine, New Haven, USA.

$\mathrm{J}$ Gen Intern Med 35(1):403

DOI: $10.1007 / \mathrm{s} 11606-019-05497-3$

(c) Society of General Internal Medicine 2019

$\mathrm{T}$ his study by Liu et al. ${ }^{1}$ examines trends in the prevalence of prediabetes as self-reported by patients, and of treatment of prediabetes with metformin, using a serial crosssectional analysis of 2005-2014 NHANES data. In their study, they defined prediabetes by self-report of prediabetes, impaired fasting glucose, impaired glucose tolerance, "borderline diabetes," or a blood sugar higher than normal but not high enough to be called diabetes or sugar diabetes. Their analysis also includes hemoglobin A1c and fasting glucose data. The authors note that $8 \%$ and $14 \%$ of self-reported prediabetics met diagnostic criteria for diabetes using HbAlc $(\geq 6.5 \%)$ or FPG $(\geq 126 \mathrm{mg} / \mathrm{dL}$ ). This may be due to progression from prediabetes to diabetes as they note, but likely also illuminates the challenges of communicating with patients about prediabetes and diabetes, which informs how patients may engage with lifestyle modification or use of metformin for prevention of disease progression.

Self-reported prediabetes has increased over time from 5.1 to $7.4 \%$ of adults. Use of self-report as a proxy for prediabetes likely significantly underestimates the actual prevalence of clinical prediabetes. We have found that in our HMO population of $>20,000$ adults, the prevalence of prediabetes using hemoglobin A1c criteria is twice that of diabetes. ${ }^{2}$ Extrapolating from NHANES data of an $8.5 \%$ prevalence of type 2 diabetes among US adults, the actual prevalence of prediabetes should be closer to $17 \%$ rather that their reported $7.4 \%$.

In order to engage in treatment to prevent diabetes, patients must first be aware that they have prediabetes. However, even among those patients with self-reported prediabetes, metformin use is low, concentrated in older adults and those who meet laboratory criteria for diabetes. Although the use of metformin in self-reported prediabetics has increased from $2.4 \%$ in 2005 to $5.5 \%$ in 2014, this study by Liu et al. shows particularly low rates of metformin use among those younger than 60, despite a grade A recommendation by the 2019 American Diabetes Association (ADA) guidelines to consider its use in this population to prevent progression to diabetes, ${ }^{3}$ based on the findings of the Diabetes Prevention Program. ${ }^{4}$

Corresponding Author: Elizabeth A. Richey, MD, MS; Yale Health and Yale School of Medicine, New Haven, USA (e-mail: elizabeth. richey@yale.edu).

\section{Compliance with Ethical Standards:}

Conflict of Interest: The authors declare that they do not have a conflict of interest.

\section{REFERENCES}

1. Liu C, Foti K, Grams ME, Shin JI, Selvin E Trends in Self-Reported Prediabetes and Metformin Use in the United States: NHANES 2005-2014. J Gen Intern Med. https://doi.org/10.1007/s11606-019-05398-5

2. Yale Health Center registry data, 2019 (unpublished)

3. American Diabetes Association. Standards of Medical Care in Diabetes 2019, S31.

4. Knowler WC, Barrett-Connor E, Fowler SE, Hamman RF, Lachin JM, Walker EA, Nathan DM. Reduction in the Incidence of Type 2 Diabetes With Lifestyle Intervention or Metformin. N Engl J Med 2016;346(6):393403.

Publisher's Note Springer Nature remains neutral with regard to jurisdictional claims in published maps and institutional affiliations.

Published online November 8, 2019 